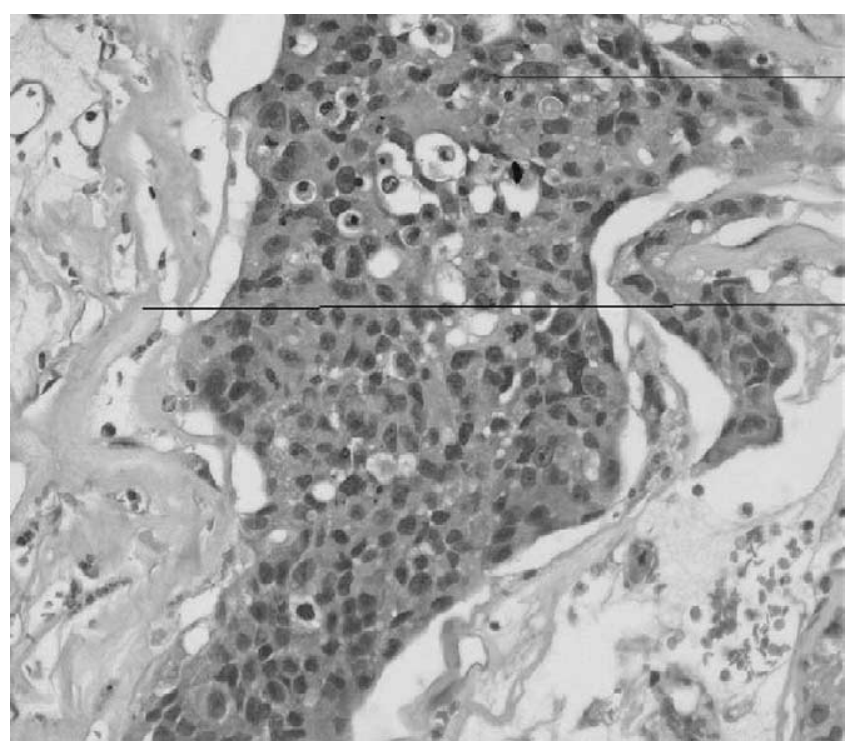

Figure 2. High-power resolution image of metastatic tumor cells (upper line) within the matrix of atrial myxoma cells (lower line).
A high index of clinical suspicion is necessary to determine the exact nature of heart tumors to optimize management of the patient.

\section{References}

1. Clemente LM, Patier JL, Lopez-Suanzes MJ, Jimenez M. Cardiac metastases form a transitional cell carcinoma: an unusual clinical manifestation. Br J Urol. 1997;80:831-2.

2. McAllister HA, Fenoglio JJ Jr. Tumors of the cardiovascular system. In: Atlas of tumor pathology, series 2. Washington (DC): Armed Forces Institute of Pathology; 1978.

3. Silverman NA. Primary cardiac tumors. Ann Surg. 1980;91:127-38.

4. Miyamoto MI, Picard MH. Left atrial mass caused by metastatic renal cell carcinoma: an unusual site of tumour involvement mimicking myxoma. $J$ Am Soc Echocardiogr. 2002;15:847-8.

5. Lang RM, Borow KM, Neumann A. Metastatic carcinoma involving the left atrium. Am Heart J. 1985;110:884-6.

\title{
Endovascular treatment of a bleeding aortic aneurysm after descending aortic aneurysm repair with island reimplantation
}

Petr Symersky, MD, ${ }^{a}$ Joris W. J. Vriend, MD, ${ }^{\mathrm{b}}$ Anje M. Spijkerboer, MD, PhD, ${ }^{\mathrm{c}}$ Barbara J. M. Mulder, MD, PhD, ${ }^{\mathrm{b}}$

Dink A. Legemate, MD, PhD, ${ }^{d}$ and Bas A. J. M. de Mol, MD, PhD, ${ }^{a}$ Amsterdam, The Netherlands

I ntercostal artery patch dilatation is uncommon after replacement of the descending aorta. It has been reported in patients with intrinsic aortic wall disease and may be challenging to manage in an emergency setting. ${ }^{1,2}$ We report the case of a patient with a rupture of an intercostal artery patch managed with an endovascular technique.

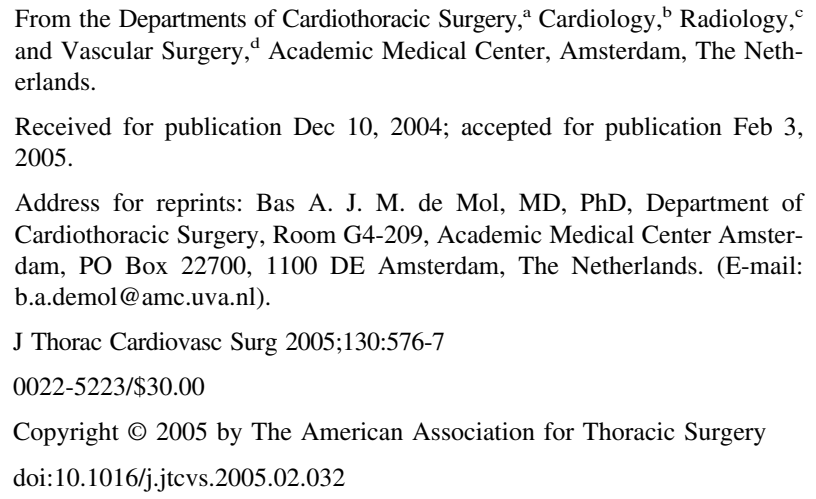
Cardiothoracic Surgery, Room G4-209, Academic Medical Center Amsterdam, PO Box 22700, 1100 DE Amsterdam, The Netherlands. (E-mail: b.a.demol@amc.uva.nl).

J Thorac Cardiovasc Surg 2005;130:576-7

$0022-5223 / \$ 30.00$

Copyright $\odot 2005$ by The American Association for Thoracic Surgery doi:10.1016/j.jtcvs.2005.02.032

\section{Clinical Summary}

A 47-year-old man with Marfan syndrome was referred for evaluation of a right-sided hemothorax. Three years previously, a type 2 thoracoabdominal aneurysm with a chronic type B dissection had been found, and the patient had undergone aortic replacement from the left subclavian artery up to the iliac arteries. A knitted Dacron vascular graft (Gelseal; Vascutek Ltd, Inchinnan, UK) was implanted with a patch containing seven intercostal arteries; another patch contained the visceral and right renal arteries, and a separate Dacron graft was connected to the left renal artery. After discharge, the patient refused follow-up computed tomographic (CT) scans.

The patient was seen with acute, tearing pain between the shoulders. At presentation, the patient was in respiratory distress and markedly hypertensive. A CT scan showed dilatation of the intercostal patch with a hematoma and primarily a right-sided pleural effusion without a clear bleeding site. Aggressive blood pressure control was instituted. After 3 days, the patient's condition deteriorated, with hemodynamic instability. Another CT scan showed a bleeding false aneurysm with a cephalad blowout of the intercostal patch (Figure 1). In an emergency setting, a Gore TAG 


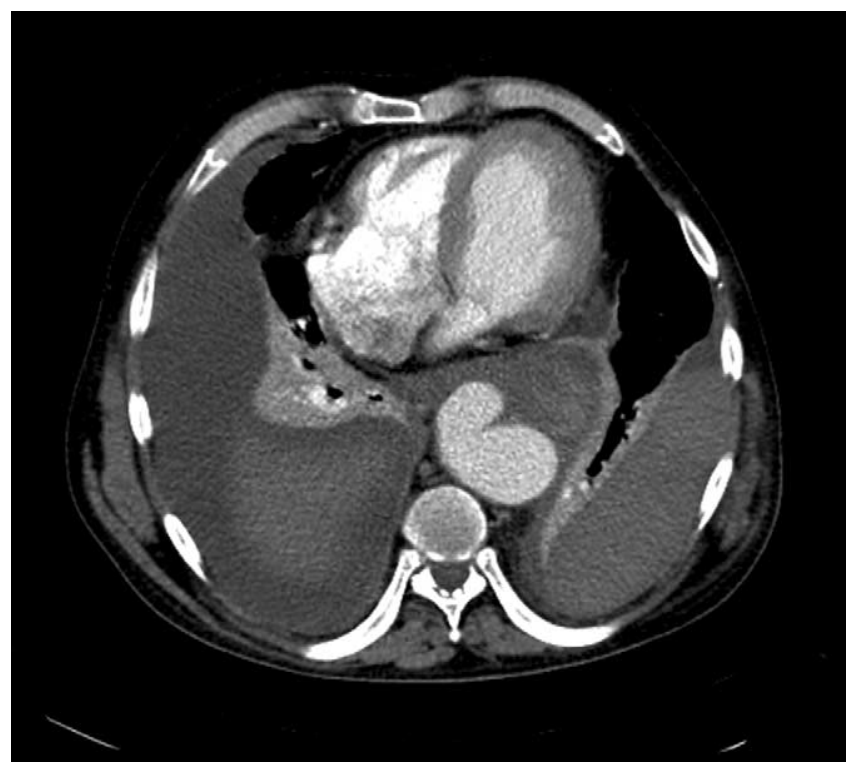

Figure 1. CT scan showing dilated intercostal patch and bilateral hemothorax.

endovascular stent graft $(40 \times 200 \mathrm{~mm}$; W.L. Gore \& Associates, Inc, Flagstaff, Ariz) was positioned $2 \mathrm{~cm}$ distal of the left subclavian artery, extending to the graft to the left renal artery (Figure 2). Spinal fluid was drained. There was mild retrograde filling of the intercostal patch (type 2 endoleak), and there was no postoperative neurologic deficit. A control CT scan confirmed adequate sealing of the aneurysm, with no retrograde filling of the patch sac. The patient had an uneventful recovery and was discharged 10 days after the operation with antihypertensive medication. A CT scan 1 month later showed a reduction of the aneurysm size with no signs of endoleak.

\section{Discussion}

Several therapeutic strategies have been used to secure spinal cord nourishment in descending aortic replacement. The en bloc technique is commonly used for intercostal artery reimplantation during replacement of the descending aorta. Dilatation and saccular aneurysm formation of visceral and intercostal patches have been reported previously, especially in patients with intrinsic aortic wall disease (such as Marfan syndrome). ${ }^{1,2}$ Separate grafting of intercostal vessels, on the other hand, may be time consuming, and the grafts are prone to kinking. This case illustrates the problems that may be encountered when using a large intercostal patch in de-

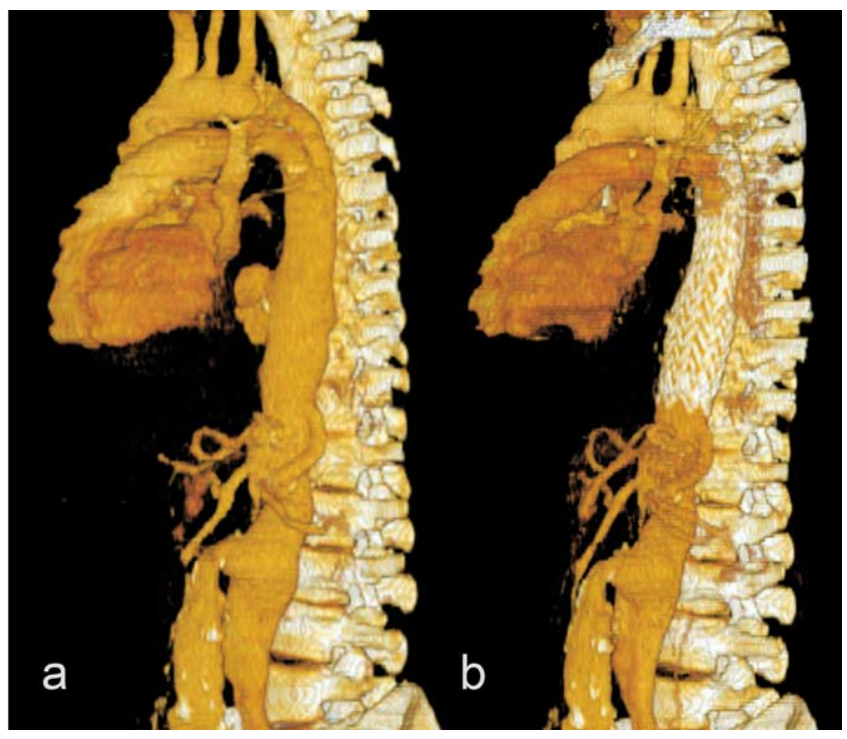

Figure 2. CT angiography of entire aorta before (a) and after (b) stent graft implantation.

scending aortic replacement in patients with intrinsic aortic wall disease. Furthermore, it underscores the necessity of follow-up.

Although stent-graft implantation in patients with Marfan syndrome who have aortic aneurysms has been reported before, intrinsic aortic wall disease has been shown to be a contraindication in all thoracic stent-graft trials. ${ }^{3}$ Stent placement prevented exsanguination in this patient, despite of the initial type 2 endoleak that could have required a more definite treatment subsequently. There was no endoleak at follow-up in this case, but vigilance and long-term surveillance are imperative when treating patients with intrinsic aortic wall disease.

\section{References}

1. Dardik A, Perler BA, Roseborough GS, Williams GM. Aneurysmal expansion of the visceral patch after thoracoabdominal aortic replacement: an argument for limiting patch size? J Vasc Surg. 2001;34:40510.

2. Vriend JW, Meijboom LJ, Nollen GJ, Jonkers RE, de Mol BA, Mulder BJ. Compression of the left main bronchus and pulmonary artery after entire aortic replacement with Dacron arterial grafts. Ann Thorac Surg. 2004;78:e54-5.

3. Fleck TM, Hutschala D, Tschernich H, Rieder E, Czerny M, Wolner E, et al. Stent graft placement of the thoracoabdominal aorta in a patient with Marfan syndrome. J Thorac Cardiovasc Surg. 2003;125:1541-3. 